\title{
Thermal Insulation Properties of Green Vacuum Insulation Panel Using Wood Fiber as Core Material
}

\author{
Baowen Wang, ${ }^{\text {a }}$ Zhihui Li, ${ }^{\text {a }}$ Xinglai Qi, ${ }^{\text {a }}$ Nairong Chen, ${ }^{\text {a }}$ Qinzhi Zeng, ${ }^{\text {a }}$ Dasong Dai, \\ Mizi Fan, ${ }^{\mathrm{a}, \mathrm{b}, *}$ and Jiuping Rao ${ }^{\mathrm{a}, *}$
}

\begin{abstract}
Wood fibers were prepared as core materials for a vacuum insulation panel (VIP) via a dry molding process. The morphology of the wood fibers and the microstructure, pore structure, transmittance, and thermal conductivity of the wood fiber VIP were tested. The results showed that the wood fibers had excellent thermal insulation properties and formed a porous structure by interweaving with one another. The optimum bulk density that led to a low-cost and highly thermally efficient wood fiber VIP was $180 \mathrm{~kg} / \mathrm{m}^{3}$ to $200 \mathrm{~kg} / \mathrm{m}^{3}$. The bulk density of the wood fiber VIP was $200 \mathrm{~kg} / \mathrm{m}^{3}$, with a high porosity of $78 \%$, a fine pore size of $112.8 \mu \mathrm{m}$, and a total pore volume of $7.0 \mathrm{~cm}^{3} \cdot \mathrm{g}^{-1}$. The initial total thermal conductivity of the wood fiber VIP was $9.4 \mathrm{~mW} /(\mathrm{m} \cdot \mathrm{K})$ at $25^{\circ} \mathrm{C}$. The thermal conductivity of the VIP increased with increasing ambient temperature. These results were relatively good compared to the thermal insulation performance of current biomass VIPs, so the use of wood fiber as a VIP core material has broad application prospects.
\end{abstract}

Keywords: Wood fiber; Vacuum insulation panel; Bulk density; Pore structure; Thermal conductivity

Contact information: a: College of Material Engineering, Fujian Agriculture and Forestry University, 63 Xiyuangong Road, Fuzhou 350002, PR China; b: College of Engineering Design and Physical Sciences, Brunel University, Uxbridge UB8 3PH, United Kingdom;

*Corresponding author: fafurjp@163.com; mizi.fan@brunel.ac.uk

\section{INTRODUCTION}

With the emergence of the international energy crisis, many countries have initiated policies of developing and saving energy. Energy conservation not only means reducing energy waste but also reducing $\mathrm{CO}_{2}$ emissions and slowing the global greenhouse effect. The promotion and application of efficient insulation materials is an effective measure to improve energy utilization. In some countries insulation materials are considered as important as coal, oil, natural gas, and nuclear energy (Palmer and Cooper 2014). Insulation materials are usually used for building enclosures or thermal equipment to save energy by reducing heat transfer, including both thermal insulation materials and cooling materials (Schiavoni et al. 2016). A vacuum insulation panel (VIP) is one of the most promising insulation materials at present. It uses vacuum technology to put a heat insulation core in a gas barrier envelope and then makes a vacuum package (Kalnaes and Jelle 2014). Under vacuum conditions, the heat transfer of VIP gas is reduced to almost zero, so its total heat transfer mainly consists of solid heat transfer and radiation heat transfer. The thermal insulation performance of VIP is 3 to 6 times that of a traditional thermal insulation material, and thermal conductivity is low, usually less than $12 \mathrm{~mW} /(\mathrm{m} \cdot \mathrm{K})$. When the same thermal insulation technology is required, the thickness is usually only $10 \mathrm{~mm}$ to $30 \mathrm{~mm}$, 
so it can greatly improve the utilization of space in construction, refrigeration, and cold chain transportation (Alam et al. 2011).

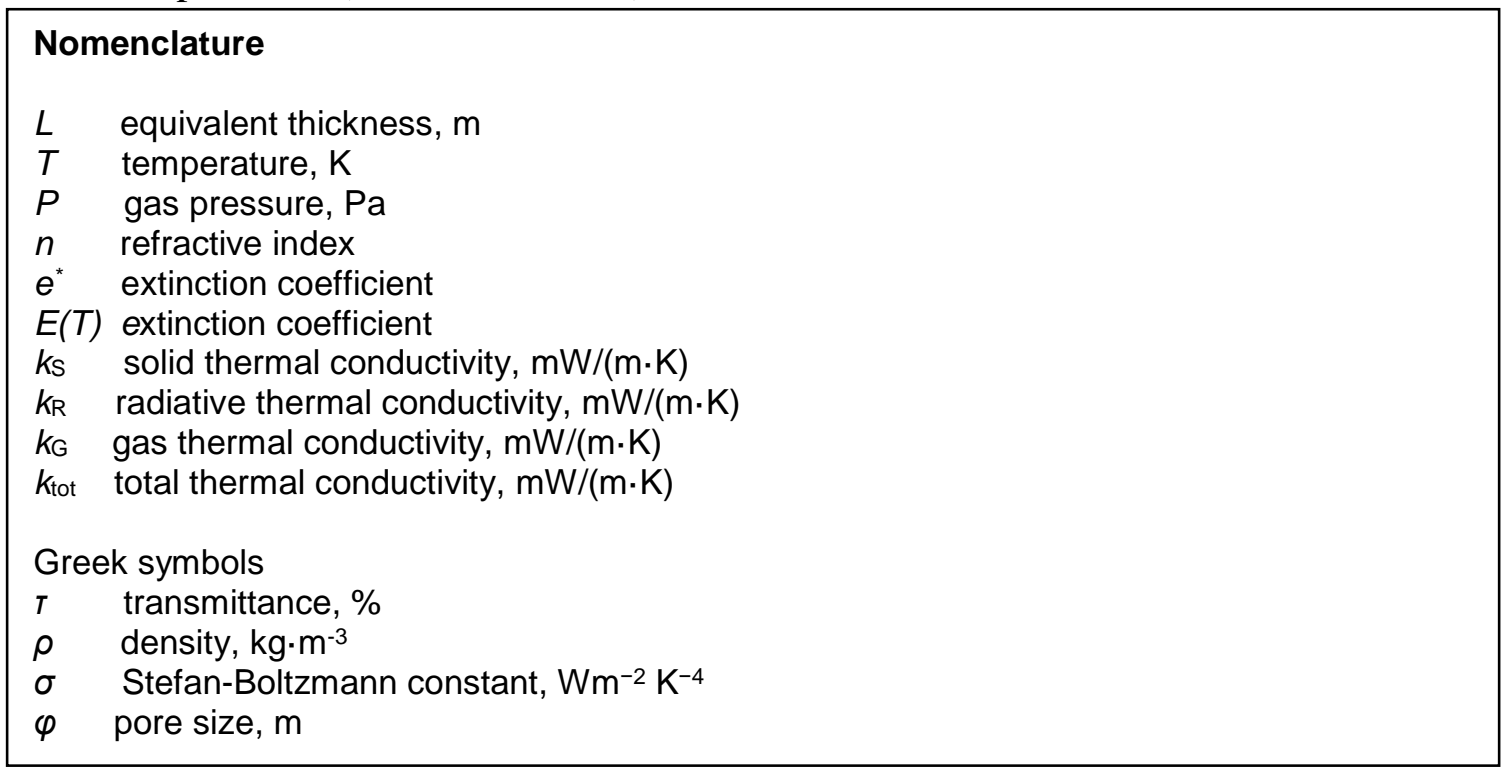

The high cost is one of the drawbacks of VIP, especially the preparation cost of the core materials, which seriously hinders its application (Almeida et al. 2017). As previously stated, the VIP is mainly composed of an insulated core material and a gas barrier envelope. The core material is the most important factor of its thermal insulation performance. The core material plays an important role in the VIP system as a skeleton material and a necessary condition to maintain the vacuum in the panel. The core material acts as a framework to support the wall of the VIP, preventing shrinkage, collapse, and direct heat transfer of the diaphragm during vacuum pumping. The internal pressure of the intact VIP is generally as low as $0.1 \mathrm{~Pa}$, and there is a great pressure difference with the atmosphere outside the panel, which will produce approximately $10^{5} \mathrm{~Pa}$ of pressure acting on the core structure. The core material needs to effectively control the heat conduction and convection of the gas in the panel. The porous structure of the core material confines the gas in the panel to a small chamber composed of pore walls. The core material needs to shield and scatter infrared radiation. In VIP under high vacuum conditions, convective heat transfer is almost zero, and radiative heat transfer is one of the main forms of heat transfer. The VIP core porous inner wall can absorb and scatter infrared heat radiation, greatly reducing radiative heat transfer. Therefore, it not only affects the solid heat transfer, gas heat transfer, and radiative heat transfer of the VIP, but it is also one of the key factors that affects the stability, size, and thermal conductivity of the core (Baetens et al. 2010). Traditional core material is usually comprised of porous materials, such as fiber (glass fiber) (Chen et al. 2015), organic foam (polyurethane foam) (Kan and Han 2012), and powder (fumed silica) (Lim et al. 2017). However, these are all chemical materials. The production process is complex and easily causes environmental pollution, the product is difficult to degrade after discarding, and the preparation cost is relatively high, especially for fumed silica (Tetlow et al. 2017).

In recent years, many scholars have begun to identify VIP core materials with excellent heat insulation and low cost (Mukhopadhyaya et al. 2008), such as expanded perlite (Alam et al. 2014), glass bubbles, and diatomaceous earth (Chang 2015). Nevertheless, the cost of preparing core material remains high, inhibiting wider use. Wood 
fiber (WF) has been a natural thermal insulation material since ancient times. It has the advantages of low cost, wide availability, recyclability, and is easily degraded. It can greatly reduce cost as a VIP core material, giving it a higher utilization value. (Kain et al. 2013; Almeida et al. 2017).

Nevertheless, only a few studies have been reported on wood fiber use for this purpose, and its practical performance has yet to be explored. Therefore, this study investigates the microstructure, pore structure, transmittance, and thermal conductivity of wood fiber VIP. The thermal insulation performances of different biomass VIPs are compared and a database for the development and application of wood fiber VIP is provided.

\section{EXPERIMENTAL}

\section{Materials}

Wood fiber with $10 \%$ water content was obtained from Furen Group Corporation Limited (Fuzhou, China). The gas barrier envelope used to prepare the VIP was obtained from Fujian Saite Corporation (Longyan, China).

\section{VIP preparation}

A dry molding process without any waste gas or sewage was used to prepare the VIP. Wood fiber of varying mass was mechanically stirred for $5 \mathrm{~min}$ to disperse and prevent the fiber reunion into a block, and it was then placed into a nylon bag before coldpressing with a metal die $(200 \mathrm{~mm} \times 200 \mathrm{~mm} \times 10 \mathrm{~mm})$ for $5 \mathrm{~min}$. The treated wood fiber was air dried in an oven at $105{ }^{\circ} \mathrm{C}$ until a constant weight was achieved. Next, the sample was placed into a gas barrier envelope and treated in the vacuum chamber for $15 \mathrm{~min}$ at 25 ${ }^{\circ} \mathrm{C}$. Finally, the packaged wood fiber was sealed at $0.1 \mathrm{~Pa}$ and $150{ }^{\circ} \mathrm{C}$ for $15 \mathrm{~min}$ to obtain a vacuumed encapsulation (a VIP) with different density.

\section{Methods}

Morphology of wood fiber

The morphological parameters of the wood fiber, such as length, were measured using a MorFi Compact device (Techpap, Grenoble, France); $0.03 \mathrm{~g}$ of dry wood fibers were added to $1000 \mathrm{~mL}$ deionized water. The suspension concentration was $30 \mathrm{mg} / \mathrm{L}$ in the standard pulp thinner. The number of fibers was set at 5000 .

\section{Radiative heat transfer measurements}

Radiation heat transfer, due to the divergence of electromagnetic waves, transfers energy from the thermal emitter to the cold acceptor. Radiation heat transfer is different from conduction and convection. It can transfer heat without medium. The thermal radiation of the wood fiber was determined using a Nicolet 380 Fourier transform infrared (FTIR) spectrometer (Thermo Fisher Scientific, Waltham, USA). During the test, $0.2 \mathrm{~g}$ of dry potassium bromide powder was mixed with $0.002 \mathrm{~g}$ of wood fiber and ground evenly. Then, a thin sheet with a diameter of $13 \mathrm{~mm}$ was pressed in a tablet press, and the infrared spectrum was measured. The resolution of the spectrometer was $1 \mathrm{~cm}^{-1}$, the range of scanning wavenumbers was $400 \mathrm{~cm}^{-1}$ to $4000 \mathrm{~cm}^{-1}$, and the number of scans was 32 .

The specific extinction coefficient was calculated using Eq. 1 (Modest 2003), 


$$
e^{*}=-\frac{\ln (\tau)}{L \rho}
$$

where $\tau$ is the transmittance of the wood fiber, and the infrared wavelength of $2.5 \mu \mathrm{m}$ to 25 $\mu \mathrm{m}$ was measured by an FTIR spectrometer. It was calculated as the ratio of the incident IR intensity to the transmitted infrared intensity of the sample. Additionally, the parameter $L$ represents the equivalent thickness (m), and $\rho$ represents the density of the monolithic sample $\left(\mathrm{kg} \cdot \mathrm{m}^{-3}\right)$.

The values of specific extinction coefficients $e^{*}$ were calculated with an accuracy of $10 \%$. Subsequently, the specific extinction coefficient $\left(e^{*}\right)$ was used in Eq. 2 to calculate the Rosseland mean extinction coefficient, $E(T)$ (Xu et al. 2015):

$$
E(T)=e^{*} \rho
$$

Radiative thermal conductivity of the wood fiber was calculated using Eq. 3 (Singh et al. 2015),

$$
k_{R}=\frac{16 n^{2} \sigma T^{3}}{3 E(T)}
$$

where $n$ is the refractive index, $\sigma$ is the Stefan-Boltzmann constant $\left(\sigma=5.67 \times 10^{-8} \mathrm{~W} \mathrm{~m}^{-2}\right.$ $\mathrm{K}^{-4}$ ), and $T$ is the mean temperature $(\mathrm{K})$.

\section{Gas thermal conductivity}

In porous solids, heat transfer is also carried out through the presence of gas molecules in the pores. The thermal conductivity of gas in porous media depends on the number of gas molecules (internal pressure) and the size of pores. Convection is generated by energy transfer due to the movement of gas or fluid. It can lead to heat transfer without direct contact of substances. At lower pressure, the convective conduction can be neglected. Therefore, the gas thermal conductivity $\left(k_{\mathrm{G}}\right)$ of the samples was calculated using Eq. 4 (Kwon et al. 2009),

$$
k_{\mathrm{G}}=k_{0} /[1+(0.032 / P \varphi)]
$$

where $k_{0}$ is the gas thermal conductivity of free still air at room temperature $\left(k_{0}=25.00\right.$ $\mathrm{mW} /(\mathrm{m} \cdot \mathrm{K})), P$ is the gas pressure in VIP panel $(\mathrm{Pa})$, and $\varphi$ is the pore size $(\mathrm{m})$.

\section{Solid thermal conductivity}

Solid conduction occurs through the structure of the core material, and heat is transferred through the physical contact of the core material particles. Under the condition of vacuum pumping, the main heat transfer mode in the core material is solid conduction. The total thermal conductivity of VIP can be approximately expressed as the sum of solid thermal conductivity, gas thermal conductivity, and radiative thermal conductivity (Li et al. 2016). In vacuum, the gas thermal conductivity is nearly zero. In this situation, the value of solid thermal conductivity can be approximately calculated by Eq. 5,

$$
k_{\mathrm{S}}=k_{\mathrm{tot}}-k_{\mathrm{R}}
$$

where $k_{\mathrm{S}}$ is the solid thermal conductivity, $k_{\text {tot }}$ is the total thermal conductivity, and $k_{\mathrm{R}}$ is the radiative thermal conductivity.

Thermal conductivity measurements 
A heat flow meter (Netzsch HFM 436; Netzsch, Ahlden, Germany) was employed to measure the thermal conductivity of the VIP. A VIP sample $(200 \mathrm{~mm} \times 200 \mathrm{~mm} \times 10$ $\mathrm{mm}$ ) was placed between the hot and cold plates, and the thermal conductivity was tested by the heat flux sensor upon reaching thermal equilibrium at a defined temperature difference and for a uniform temperature gradient throughout the sample. The temperature difference between the hot and cold plates was set to $20^{\circ} \mathrm{C}$, and the five temperatures at the cold plate were $5{ }^{\circ} \mathrm{C}, 15^{\circ} \mathrm{C}, 25^{\circ} \mathrm{C}, 35^{\circ} \mathrm{C}$, and $45^{\circ} \mathrm{C}$.

Scanning electron microscopy (SEM) analysis

A sample with dimensions of $10 \mathrm{~mm} \times 10 \mathrm{~mm} \times 5 \mathrm{~mm}$ was cut from a VIP panel, and the gas barrier envelope was discarded, to display its surface. The surface of the sample was examined using an emission scanning electron microscope (Nova NanoSEM 230; FEI Company, Tokyo, Japan) at an accelerating voltage of $1.0 \mathrm{kV}$.

\section{Pore structure}

Pore structure has a certain effect on solid, gas, and radiation heat transfer of materials, so it is very important for the study of VIP. The porosity, pore size, and total pore volume of the composite core were measured using an AutoPore III 9420 automatic mercury intrusion porosimeter (MIP; Micromeritics, Norcross, GA, USA). The exhaust pressure, exhaust time, mercury filling pressure, and equilibrium stability time were 50 $\mu \mathrm{mHg}, 5 \mathrm{~min}, 0.53 \mathrm{psia}$, and $5 \mathrm{~s}$, respectively.

\section{RESULTS AND DISCUSSION}

\section{Morphology of Wood Fiber}

The distribution of the lengths of wood fibers is shown in Fig. 1. The lengths of wood fibers were mainly distributed in the range of $0.5 \mathrm{~mm}$ to $1.0 \mathrm{~mm}(77.7 \%)$. The average wood fiber length was $0.93 \mathrm{~mm}$. Because the core material of wood fiber was made by dry molding without any adhesive, the core material mainly depends on the interweaving of the fibers. Longer fibers can act as the skeleton, while shorter fibers can fill gaps in the skeleton, forming a compact structure.

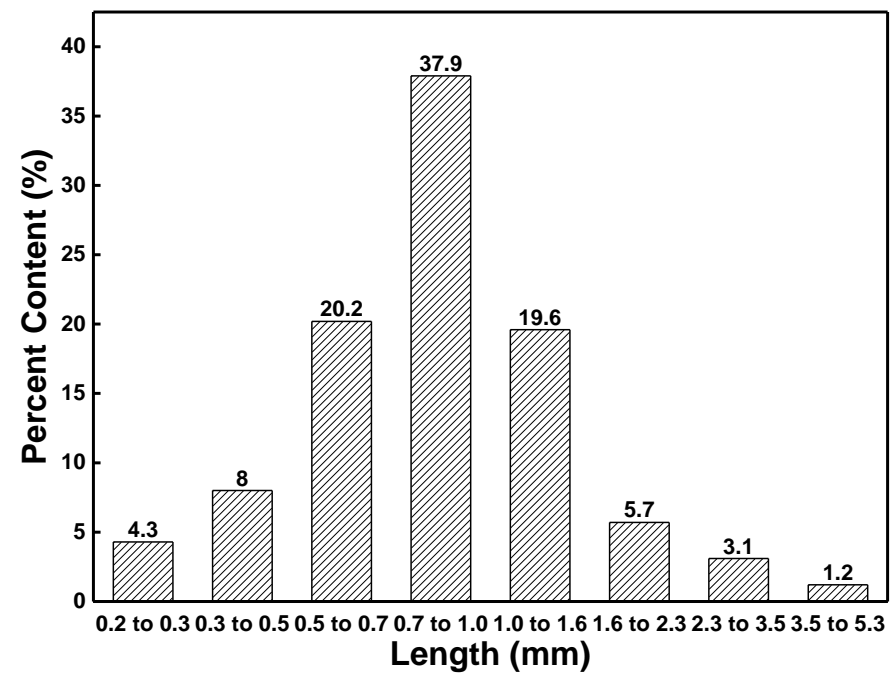


Fig. 1. The length distribution of wood fibers

\section{Effect of Bulk Density on Thermal Conductivity}

Bulk density is an important parameter for the core material to measure heat insulation performance. High bulk density enhances the heat transfer of solids and also reduces the porosity of the core material, which inhibits the discharge of gas in the later vacuum packaging process. Conversely, core material with too low bulk density is difficult to form and liable to collapse in the packaging process. Therefore, the core bulk density is directly related to the performance of VIP.

The panel thermal conductivity measurements for the five VIPs with different densities are shown Fig. 2. All of the five VIP samples possessed a thermal conductivity of $9.1 \mathrm{~mW} /(\mathrm{m} \cdot \mathrm{K})$ to $21.7 \mathrm{~mW} /(\mathrm{m} \cdot \mathrm{K})$. The VIP thermal conductivity slowly increased with increasing density when density was less than $240 \mathrm{~kg} / \mathrm{m}^{3}$ but it greatly increased as the density reached $260 \mathrm{~kg} / \mathrm{m}^{3}$. An increase in bulk density led to gradual increases in both the contact area between fibers and the solid thermal conductivity. When bulk density reached a certain value, part of the pore collapsed, the porosity rapidly decreased, and the thermal conductivity rapidly increased. In addition, excessive bulk density also made part of the pore change from open to closed, such that part of the original air still remained in the pore. It is difficult to discharge gas from the gap during vacuum evacuation, which led to increased gas thermal conductivity. Therefore, in a certain range, the volume weight of the VIP core material should be reduced as much as possible. The overall thermal conductivity increased as the density increased. Although the VIP required less strength for the core material, the low bulk density of the core material can easily cause the low strength of the panel and collapse during the vacuum evacuation process, resulting in the uneven surface of VIP. Thus, the core material density must not be too low. According to the comprehensive analysis, the optimum bulk density of wood fiber VIP was $200 \mathrm{~kg} / \mathrm{m}^{3}$, and its thermal conductivity was $9.4 \mathrm{~mW} /(\mathrm{m} \cdot \mathrm{K})$.

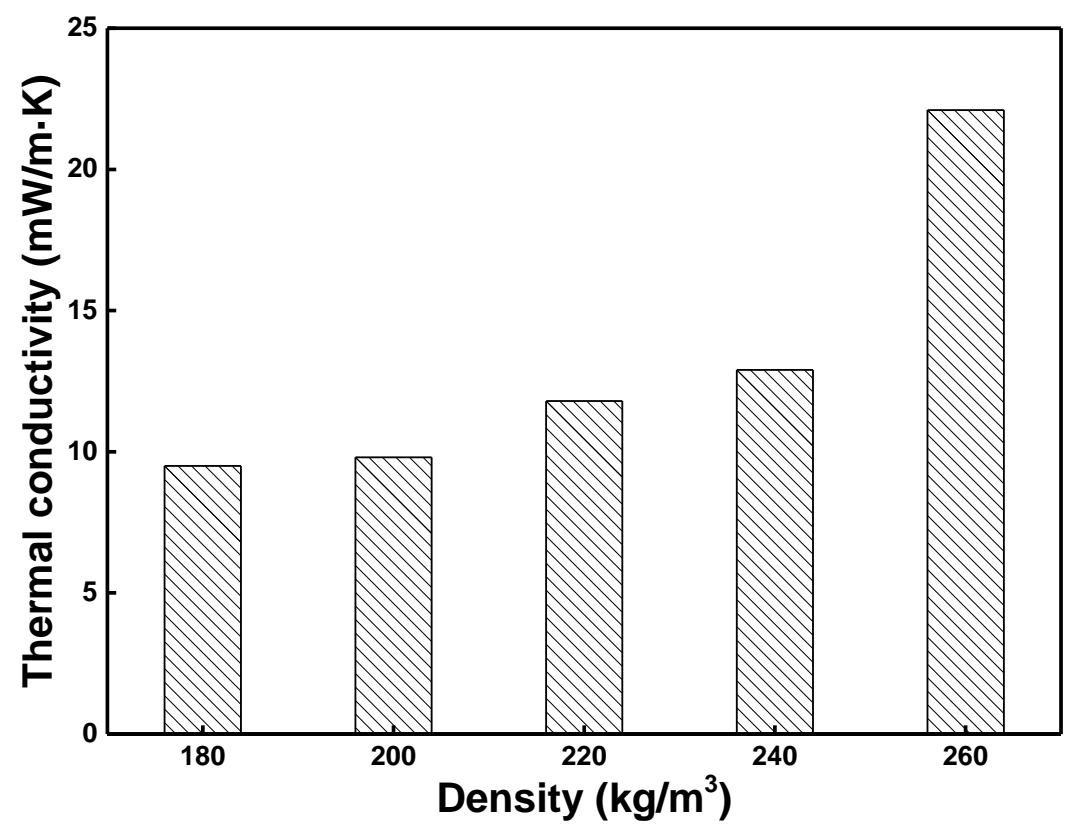

Fig. 2. Thermal conductivity measurements of VIP panels with wood fiber core materials of different densities 


\section{Effect of Temperature on Thermal Conductivity}

The thermal conductivity of wood fiber VIP $\left(200 \mathrm{~kg} / \mathrm{m}^{3}\right)$ at various temperatures is shown in Fig. 3. The thermal conductivity of the five samples increased with increasing temperature, from $9.1 \mathrm{~mW} /(\mathrm{m} \cdot \mathrm{K})$ to $13.8 \mathrm{~mW} /(\mathrm{m} \cdot \mathrm{K})$ when the temperature increased from $15^{\circ} \mathrm{C}$ to $55^{\circ} \mathrm{C}$. This result was mainly because the radiative thermal conductivity was directly proportional to the cube of temperature. With increasing temperature, the radiative thermal conductivity of VIP increases and the total thermal conductivity increases (Singh et al. 2015).

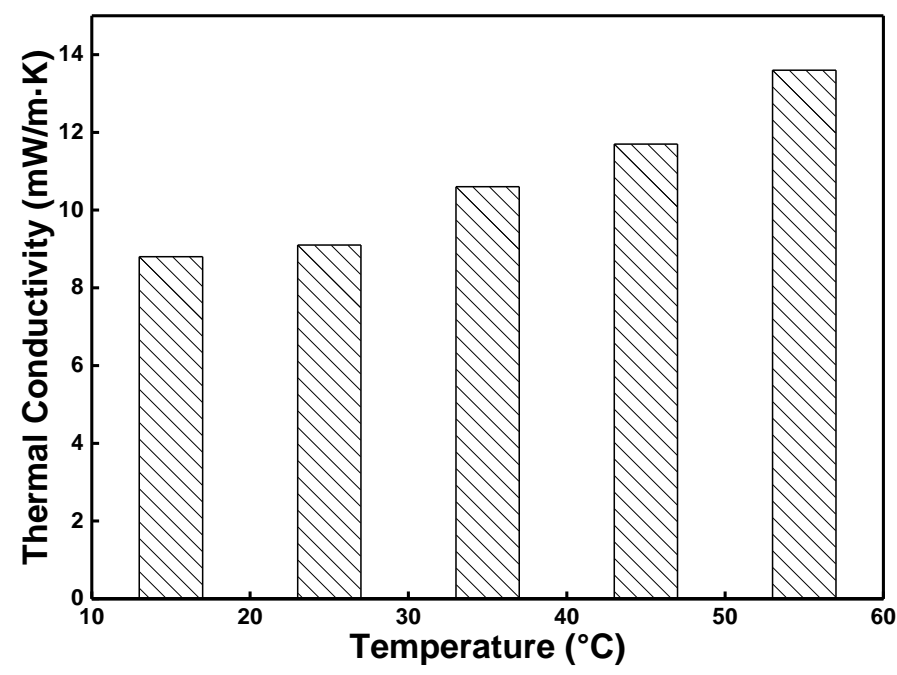

Fig. 3. Thermal conductivity of wood fiber VIP $\left(200 \mathrm{~kg} / \mathrm{m}^{3}\right)$ at various temperatures

\section{Radiative Heat Transfer Measurements}

When there is a temperature gradient between objects, heat transfer will spontaneously occur from high to low temperature. In addition, the heat flux in the wood fiber core material with open structure will be the superposition of solid, gas, and radiative heat transfers (Brodt 1995). After vacuum treatment, the heat transfer of the gas in VIP stopped; thus, solid and radiative heat transfers were the applicable forms in VIP.

Thermal radiation is the phenomenon in which a body emits radiant energy outward due to the thermal movement of microscopic particles in the body, or the temperature of the body itself (Simmler et al. 2005). In essence, thermal radiation is the process of emitting electromagnetic waves outward as heat. The wavelength range of electromagnetic waves is from $10^{-6} \mu \mathrm{m}$ to $10^{9} \mu \mathrm{m}$, and only $0.1 \mu \mathrm{m}$ to $100 \mu \mathrm{m}$ electromagnetic waves result from thermal effects, including visible light, partial infrared, and ultraviolet light (Rettelbach et al. 1995). Radiative heat transfer is different from conduction and convection, as it does not require any medium. As long as the temperature of the object is greater than absolute zero, the object will continuously radiate energy, that is, transfer energy in the form of photons from the surface. Radiative heat transfer also contributed to the heat transfer of VIP, even reaching as great as $50 \%$ of the overall thermal conductivity. Therefore, radiative thermal conductivity was one of the key factors that affected the stability of the thermal conductivity of VIP, which was mainly related to the transmittance and density of the core material (Fricke et al. 2006). Radiative heat transfer is due to the divergence of electromagnetic waves, which yields energy transfer from the heat emitter to the cold receiver. Under vacuum conditions, the radiative thermal conductivity of wood fiber VIP accounts for a large part of the total thermal conductivity. Figure 4 shows the transmittance 
of the wood fiber measured by the FTIR spectrometer. After measuring the transmittance of the material via infrared spectroscopy, the radiative thermal conductivity of the core material was calculated according to the formula in Eqs. 1 through 3. At room temperature, the wood fiber VIP with bulk density of $200 \mathrm{~kg} / \mathrm{m}^{3}$ had a radiative thermal conductivity of $2.3 \mathrm{~mW} /(\mathrm{m} \cdot \mathrm{K})$, accounting for $24.5 \%$ of the total thermal conductivity. According to Eq. 3 , the radiative thermal conductivity increased with increasing temperature. Figure 5 shows the radiative thermal conductivity of wood fiber VIP at different ambient temperatures. The radiative thermal conductivity of the wood fiber was $2.1 \mathrm{~mW} /(\mathrm{m} \cdot \mathrm{K})$ when the ambient temperature was $15^{\circ} \mathrm{C}$. When the ambient temperature was $55^{\circ} \mathrm{C}$, the radiative thermal conductivity was $3.0 \mathrm{~mW} /(\mathrm{m} \cdot \mathrm{K})$, which was an increase of $42.9 \%$.

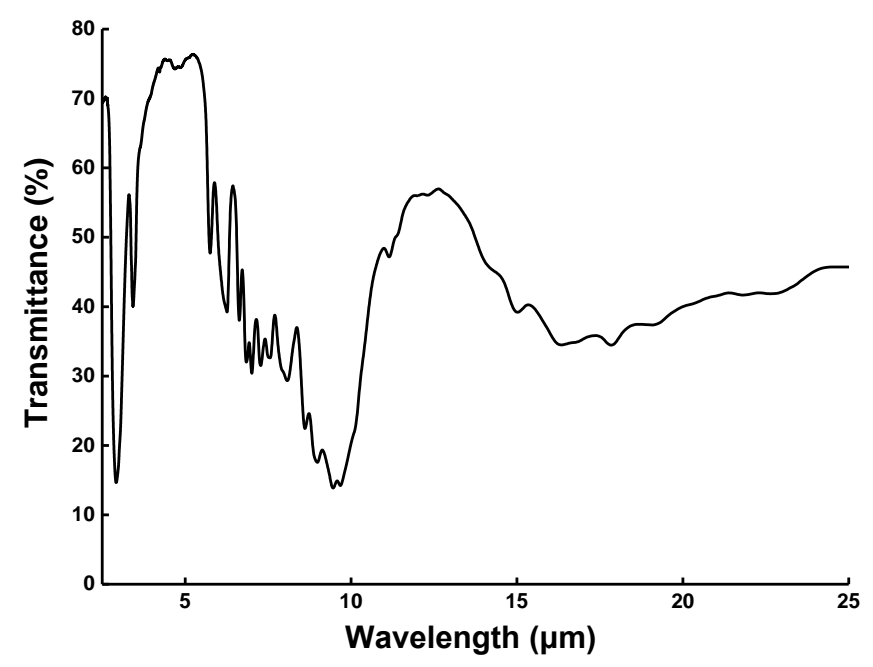

Fig. 4. Transmittance of the wood fiber samples measured by FTIR spectrometer

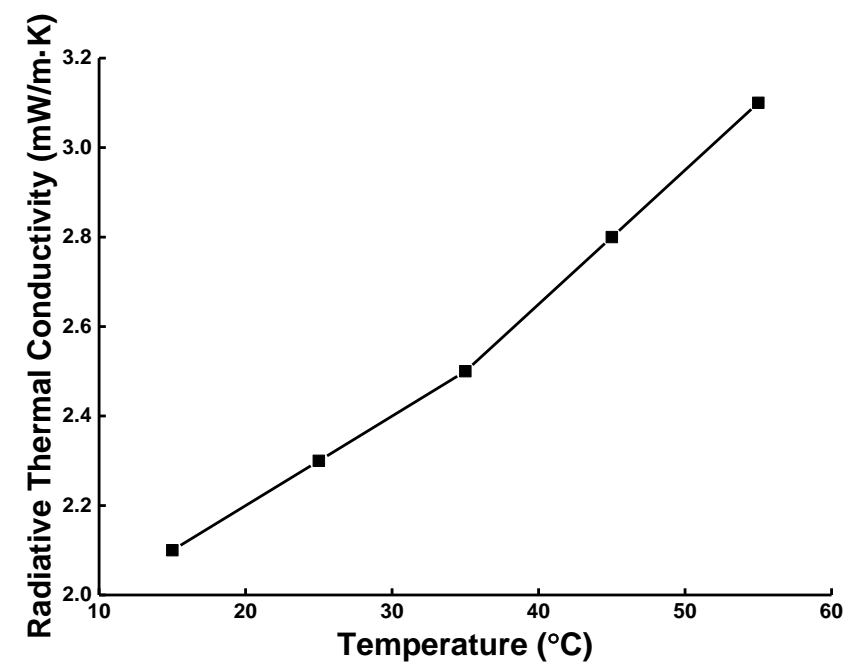

Fig. 5. Radiative thermal conductivity of wood fiber VIP at various temperatures

\section{Solid Thermal Conductivity}

As shown in Figs. 2 and 5, the total thermal conductivity and radiative thermal conductivity of VIP with bulk density of $200 \mathrm{~kg} / \mathrm{m}^{3}$ were $9.4 \mathrm{~mW} /(\mathrm{m} \cdot \mathrm{K})$ and 2.3 $\mathrm{mW} /(\mathrm{m} \cdot \mathrm{K})$ at room temperature, respectively. The application of Eq. 5 showed that the solid thermal conductivity of VIP was $7.1 \mathrm{~mW} /(\mathrm{m} \cdot \mathrm{K})$, accounting for $75.5 \%$ of the total 
thermal conductivity. Therefore, the solid thermal conductivity played a decisive role in the heat transfer process of VIP at room temperature.

\section{SEM Analysis}

Figure 6 shows the micromorphology of the wood fiber core. As shown in Fig. 6(a), the curled wood fibers intertwined with one another to form a porous structure, which was conducive to the thermal insulation of the core material. Figure $6(\mathrm{~b})$ displays the many single holes and cross-field holes on the wood fiber with low weight and porous properties, which are beneficial for its heat insulation performance (Kwon et al. 2009).
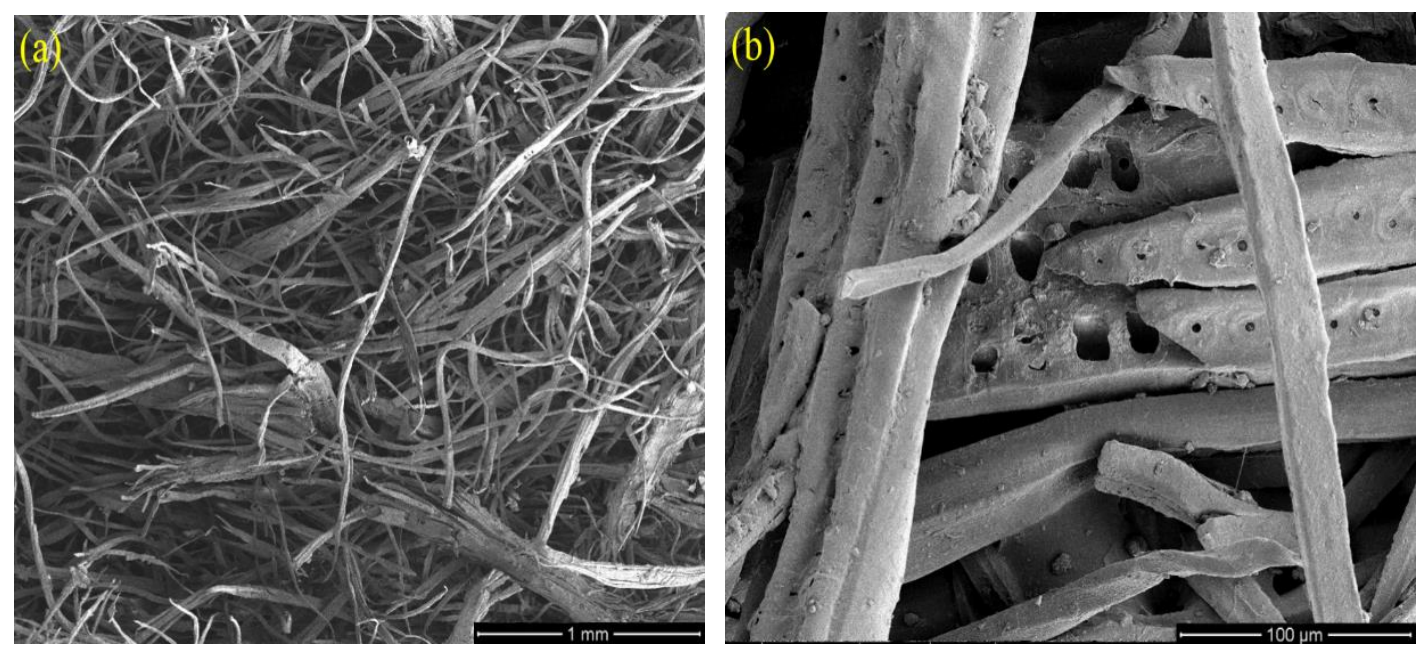

Fig. 6. SEM micrographs of wood fiber core: (a) $\times 100$, and (b) $\times 1000$

\section{Pore Structure Characterization}

The thermo-physical behaviors of a porous material are directly related to its porous structure, which is described by pore volume, porosity, and pore size (Brunner et al. 2014). These parameters were tested by mercury intrusion porosimetry. The pore structure parameters for the wood fiber core are given in Table 1 . The wood fiber core board with a bulk density of $200 \mathrm{~kg} / \mathrm{m}^{3}$ was highly porous, with a porosity of $78 \%$. The total pore volume and average pore size were calculated as $7.0 \mathrm{~cm}^{3} \cdot \mathrm{g}^{-1}$ and $112.8 \mu \mathrm{m}$, respectively, by the porosimeter's software package. According to Eq. 4, the gas thermal conductivity of the core material was approximately $24.9 \mathrm{~mW} /(\mathrm{m} \cdot \mathrm{K})$ at ambient temperature and pressure.

Table 1. Pore Structure Parameters for Wood Fiber Core

\begin{tabular}{|c|c|c|c|}
\hline Average Pore Size $(\mu \mathrm{m})$ & Total Pore Volume $\left(\mathrm{cm}^{3} \cdot \mathrm{g}^{-1}\right)$ & Porosity $(\%)$ & Bulk Density $\left(\mathrm{kg} \cdot \mathrm{m}^{-3}\right)$ \\
\hline 112.8 & 7.0 & 78 & 200 \\
\hline
\end{tabular}




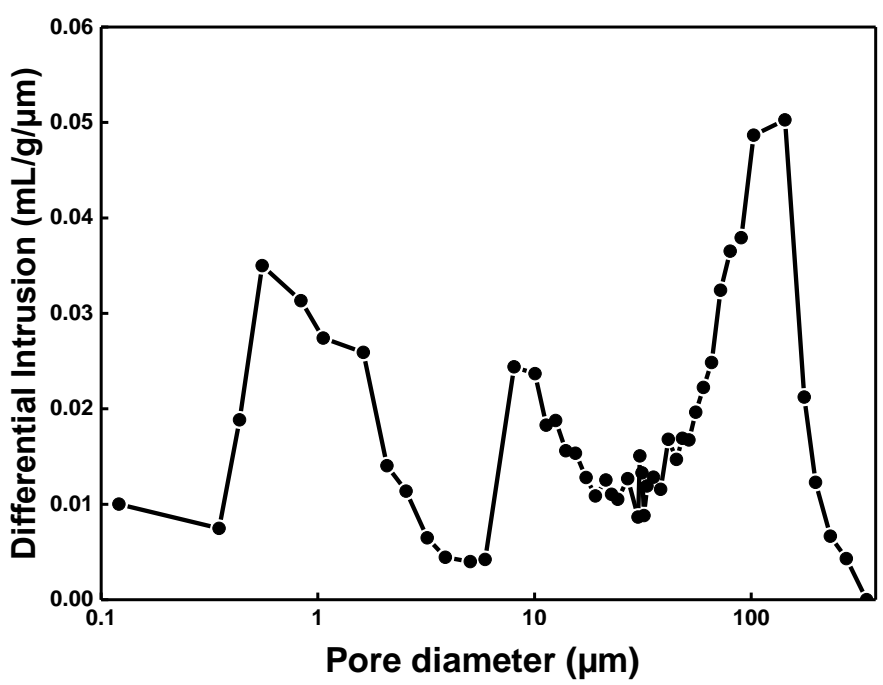

Fig. 7. Distribution of differential intrusion in the wood fiber core board calculated by MIP technique

Figure 7 shows the distribution of differential intrusion in the wood fiber core board with a bulk density of $200 \mathrm{~kg} / \mathrm{m}^{3}$. The differential intrusion curve refers to the incremental specific volume of invading mercury divided by the difference between the pore size at one boundary of the increment and the pore size at another boundary. Therefore, the differential intrusion curve can well reflect the number of pores in the pore structure of the corresponding core material. Large pores were the primary feature of the wood fiber core material, and the sizes of most pores were in the range of $0.6 \mu \mathrm{m}$ to $145 \mu \mathrm{m}$. There were three peaks $(0.6 \mu \mathrm{m}, 8.2 \mu \mathrm{m}$, and $145 \mu \mathrm{m})$ in the curve. This result may have been because the pores in the core material were mainly composed of the holes on the fiber (i.e., 0.6- $\mu \mathrm{m}$ small pores) and interweaved between the fibers (i.e., 145- $\mu \mathrm{m}$ large pores).

\section{Comparison with Previous Research (Biomass VIP)}

Biomass raw materials not only have good thermal insulation performance but also meet the requirements of green environmental protection for materials. Therefore, many kinds of biomass materials are used as the core material for VIPs. Some properties of the biomass-based VIPs from previous research are listed in Table 2. Table 2 shows that the density of a mostly biomass VIP core (except the diatomaceous earth) was lower than 220 $\mathrm{kg} / \mathrm{m}^{3}$, and the porosity was greater than $70 \%$. These properties greatly contributed to the excellent insulation performance of the biomass-based VIP. The thermal conductivity $(9.4$ $\mathrm{mW} /(\mathrm{m} \cdot \mathrm{K}))$ in this study was notably lower than the results in previously published studies pertaining to biomass VIPs. Moreover, the wood fiber core VIP was readily prepared. The VIP in this study showed promise for successful application. 
Table 2. Comparison of Biomass VIPs

\begin{tabular}{|c|c|c|c|c|}
\hline Core Material & $\begin{array}{c}\text { Density of Core } \\
\text { Material }\left(\mathrm{kg} / \mathrm{m}^{3}\right)\end{array}$ & $\begin{array}{c}\text { Thermal } \\
\text { Conductivity } \\
(\mathrm{mW} /(\mathrm{m} \cdot \mathrm{K}))\end{array}$ & $\begin{array}{c}\text { Porosity } \\
(\%)\end{array}$ & Source \\
\hline Wood fiber & 200 & 9.4 & 78 & This work \\
\hline Bamboo fibers & - & 12.6 & 75.7 & Dong et al. $(2017)$ \\
\hline Sawdust powder & 200 & 10.5 & 83.1 & Tu et al. $(2018)$ \\
\hline Cellulosic-crystals & 140 & 12.5 & - & Tetlow et al. $(2017)$ \\
\hline Diatomaceous earth & 610 & 10 & 72 & Chang $(2015)$ \\
\hline Expanded cork & - & 20 & - & Zhuang et al. $(2017)$ \\
\hline $\begin{array}{c}\text { Fumed silica/rice } \\
\text { husk ash hybrid }\end{array}$ & 217 & 9.6 & 80.5 & Li et al. $(2016)$ \\
\hline
\end{tabular}

\section{CONCLUSIONS}

1. A wood fiber VIP was prepared via a dry molding process. Wood fibers were interwoven to form a porous spatial structure without any adhesives. The production process of the VIP was simple, and no sewage was generated. Its application prospects are very good.

2. Increasing the bulk density of wood fiber VIP had a negative effect on the panels' heat insulation properties. The $180 \mathrm{~kg} / \mathrm{m}^{3}$ to $200 \mathrm{~kg} / \mathrm{m}^{3}$ panels showed better results for thermal conductivity.

3. At room temperature, the wood fiber VIP with a bulk density of $200 \mathrm{~kg} / \mathrm{m}^{3}$ had a thermal conductivity of $9.4 \mathrm{~mW} /(\mathrm{m} \cdot \mathrm{K})$, of which the solid and radiative thermal conductivities were $7.1 \mathrm{~mW} /(\mathrm{m} \cdot \mathrm{K})$ and $2.3 \mathrm{~mW} /(\mathrm{m} \cdot \mathrm{K})$, respectively. The porosity was $78 \%$, the average pore diameter was $112.8 \mu \mathrm{m}$, and the total pore volume was 7.0 $\mathrm{cm}^{3} \cdot \mathrm{g}^{-1}$.

\section{ACKNOWLEDGEMENTS}

The authors are grateful for the financial supports of Science \& Technology Program in Fujian Province of China (2017N3009) and Science \& Technology Innovation Program in Fujian Agriculture and Forestry University of China (CXZX2017375 ).

\section{REFERENCES CITED}

Alam, M., Singh, H., Brunner, S., and Naziris, C. (2014). "Experimental characterisation and evaluation of the thermo-physical properties of expanded perlite-Fumed silica composite for effective vacuum insulation panel (VIP) core," Energy and Buildings 69, 442-450. DOI: 10.1016/j.enbuild.2013.11.027

Alam, M., Singh, H., and Limbachiya, M. C. (2011). "Vacuum insulation panels (VIPs) for building construction industry - A review of the contemporary developments and future directions," Applied Energy 88(11), 3592-3602. DOI:

10.1016/j.apenergy.2011.04.040 
Almeida, F. A., Corker, J., Ferreira, N., Neto, M. A., Fan, M., Beyrichen, H., and Caps, R. (2017). "Alternative low cost based core systems for vacuum insulation panels," Ciência \& Tecnologia dos Materiais 29(1), e151-e156. DOI:

10.1016/j.ctmat.2016.10.002

Baetens, R., Jelle, B. P., Thue, J. V., Tenpierik, M. J., Grynning, S., Uvsløkk, S., and Gustavsen, A. (2010). "Vacuum insulation panels for building applications: A review and beyond," Energy and Buildings 42(2), 147-172. DOI: 10.1016/j.enbuild.2009.09.005

Brodt, K. H. (1995). "Thermal insulations: CFC-alternatives and vacuum insulation," Bulletin Des Sociétés Chimiques Belges 79(2-3), 283-290.

Brunner, S., Wakili, K. G., Stahl, T., and Binder, B. (2014). "Vacuum insulation panels for building applications - Continuous challenges and developments," Energy and Buildings 85, 592-596. DOI: 10.1016/j.enbuild.2014.09.016

Chang, B. S. K. (2015). Vacuum Insulation Panel Core Materials and Modelling the Thermal Conductivity of Granular Materials, Master's Thesis, Iowa State University, Ames, IA, USA.

Chen, Z., Chen, Z., Yang, Z., Hu, J., Yang, Y., Chang, L., Lee, L. J., and Xu, T. (2015). "Preparation and characterization of vacuum insulation panels with super-stratified glass fiber core material," Energy 93(Part 1), 945-954. DOI: 10.1016/j.energy.2015.08.105

Dong, X., Dai, D., Fan, H., Zhao, W., Li, Y., Zhao, H., Wu, H., Huang, L., and Chen, L. (2017). "Structure and property of the vacuum core material of insulation panel made of the bamboo fibers," China Pulp \& Paper 36(12), 45-50.

Fricke, J., Schwab, H., and Heinemann, U. (2006). "Vacuum insulation panels - Exciting thermal properties and most challenging applications," International Journal of Thermophysics 27(4), 1123-1139. DOI: 10.1007/s10765-006-0106-6

Kain, G., Barbu, M. C., Hinterreiter, S., Richter, K., and Petutschnigg, A. (2013). "Using bark as a heat insulation material," BioResources 8(3), 3718-3731. DOI: 10.15376/biores.8.3.3718-3731

Kalnaes, S. E., and Jelle, B. P. (2014). "Vacuum insulation panel products: A state-ofthe-art review and future research pathways," Applied Energy 116(3), 355-375. DOI: 10.1016/j.apenergy.2013.11.032

Kan, A. K., and Han, H. D. (2012). "Research on open-cell rigid polyurethane foam as vacuum insulated panel core," Advanced Materials Research 535-537, 1573-1576. DOI: 10.4028/www.scientific.net/AMR.535-537.1573

Kwon, J.-S., Jang, C. H., Jung, H., and Song, T.-H. (2009). "Effective thermal conductivity of various filling materials for vacuum insulation panels," International Journal of Heat and Mass Transfer 52(23-24), 5525-5532. DOI:

10.1016/j.ijheatmasstransfer.2009.06.029

Li, C.-D., Saeed, M.-U., Pan, N., Chen, Z.-F., and Xu, T.-Z. (2016). "Fabrication and characterization of low-cost and green vacuum insulation panels with fumed silica/rice husk ash hybrid core material," Materials \& Design 107, 440-449. DOI: 10.1016/j.matdes.2016.06.071

Lim, T., Seok, J., and Kim, D. D. (2017). “A comparative study of energy performance of fumed silica vacuum insulation panels in an apartment building," Energies 10(12), 2000. DOI: $10.3390 /$ en 10122000

Modest, M. F. (2003). "Radiative heat transfer," International Journal of Heat \& Mass Transfer 12(10), 1331-1337. 
Mukhopadhyaya, P., Kumaran, K., Normandin, N., Van Reenen, D., and Lackey, J. (2008). "High-performance vacuum insulation panel: Development of alternative core materials," Journal of Cold Regions Engineering 22(4), 103-123. DOI: 10.1061/(ASCE)0887-381X(2008)22:4(103)

Palmer, J., and Cooper, I. (2014). United Kingdom Housing Energy Fact File: 2013, Department of Energy \& Climate Change, London, UK.

Rettelbach, T., Säuberlich, J., Korder, S., and Fricke, J. (1995). "Thermal conductivity of silica aerogel powders at temperatures from 10 to $275 \mathrm{~K}$," Journal of Non-Crystalline Solids 186, 278-284. DOI: 10.1016/0022-3093(95)00051-8

Schiavoni, S., D’Alessandro, F., Bianchi, F., and Asdrubali, F. (2016). "Insulation materials for the building sector: A review and comparative analysis," Renewable and Sustainable Energy Reviews 62, 988-1011. DOI: 10.1016/j.rser.2016.05.045

Simmler, H., Brunner, S., Heinemann, U., Schwab, H., Kumaran, K., Mukhopadhyaya, P., Quénard, D., Sallée, H., Noller, K., Kücükpinar-Niarchos, E., et al. (2005). Vacuum Insulation Panels: Study on VIP-components and Panels for Service Life Prediction of VIP in Building Applications (A. Subtask), International Energy Agency, Paris, France.

Singh, H., Geisler, M., and Menzel, F. (2015). "Experimental investigations into thermal transport phenomena in vacuum insulation panels (VIPs) using fumed silica cores," Energy and Buildings 107, 76-83. DOI: 10.1016/j.enbuild.2015.08.004

Tetlow, D., Simon, L. D., Liew, S. Y., Hewakandamby, B., Mack, D., Thielemans, W., and Riffat, S. (2017). "Cellulosic-crystals as a fumed-silica substitute in vacuum insulated panel technology used in building construction and retrofit applications," Energy and Buildings 156, 187-196. DOI: 10.1016/j.enbuild.2017.08.058

Tu, C., Zhao, W., Dai, D., and Fan, M. (2018). "Preparation and properties of vacuum insulation panels from sawdust," Journal of Forestry Engineering 3(1), 32-37. DOI: 10.13360/j.issn.2096-1359.2018.01.006

$\mathrm{Xu}$, L., Jiang, Y., Feng, J., Feng, J., and Yue, C. (2015). "Infrared-opacified $\mathrm{Al}_{2} \mathrm{O}_{3}-\mathrm{SiO}_{2}$ aerogel composites reinforced by $\mathrm{SiC}$-coated mullite fibers for thermal insulations," Ceramics International 41(1), 437-442. DOI: 10.1016/j.ceramint.2014.08.088

Zhuang, J., Ghaffar, S. H., Fan, M., and Corker, J. (2017). "Restructure of expanded cork with fumed silica as novel core materials for vacuum insulation panels," Composites Part B: Engineering 127, 215-221. DOI: 10.1016/j.compositesb.2017.06.019

Article submitted: November 17, 2018; Peer review completed: February 24, 2019; Revised version received: February 29, 2019; Accepted: March 1, 2019; Published: March 6, 2019.

DOI: 10.15376/biores.14.2.3339-3351 